\title{
Changes in Vitamin $E$ and $\beta$-Carotene Contents in Various Edible Cassava Leaves (Manihot esculenta Crantz) of Different Ages across Multiple Seasons
}

\author{
Alphonse Laya $\mathbb{D}^{1,2}$ and Benoît B. Koubala ${ }^{1,2}$ \\ ${ }^{1}$ Department of Biological and Chemistry Sciences, Faculty of Science, University of Maroua, P. O. Box 46, Maroua, Cameroon \\ ${ }^{2}$ Department of Life and Earth Sciences, Higher Teachers' Training College of Maroua, University of Maroua, P. O. Box 55, \\ Maroua, Cameroon \\ Correspondence should be addressed to Alphonse Laya; laya.alphonse@yahoo.fr
}

Received 23 November 2019; Revised 19 May 2020; Accepted 26 May 2020; Published 12 June 2020

Academic Editor: Kent Burkey

Copyright (C) 2020 Alphonse Laya and Benoît B. Koubala. This is an open access article distributed under the Creative Commons Attribution License, which permits unrestricted use, distribution, and reproduction in any medium, provided the original work is properly cited.

\begin{abstract}
Vitamin $\mathrm{E}$ and carotenoids belong to a group of bioactive compounds that have an important effect on human health. The present study aims to investigate for the first time the concentration of vitamin $\mathrm{E}, \alpha$-, $\gamma$-, and $\delta$-tocopherol, and $\beta$-carotene in edible cassava leaves during different ages. The analysis was performed using colorimetry and high-performance liquid chromatograph (HPLC) methods. A significant difference was found among $\alpha$-, $\gamma$-, and $\delta$-tocopherol concentrations in leaves; $\gamma$-and $\alpha$-tocopherol isomer contents were the predominant in amount, respectively. Among the leaves, AD variety harvested at 6 months after planting (MAP) was the highest in total vitamin E $(222 \mu \mathrm{g} \alpha$-TE/g). However, the highest $\gamma$-tocopherol content $(2782 \mu \mathrm{g} / 100 \mathrm{~g})$ and the content of biologically active vitamin E $(1244 \mu \mathrm{g} / 100 \mathrm{~g})$ were found in EN variety at 6MAP, whereas the highest value $(42 \mu \mathrm{g} / \mathrm{g}) \mathrm{of}$ $\beta$-carotene was found in AD variety at 12MAP. Total vitamin $\mathrm{E}$ and tocopherol isomers composition varied among varieties and seasons as did $\beta$-carotene. The effects of varieties and harvest ages on the biosynthesis regulation of these compounds were confirmed by principal component analysis (F1x F2: 74.34\%). Edible cassava leaves can be considered as sources of vitamin E for natural dietary antioxidant during different ages, and the best time to harvest EN and AD varieties is at 6MAP on the basis of $\alpha$-tocopherol equivalent or content of biologically active vitamin E content, and EN and AD varieties performed the overall best. Thus, the edible cassava leaves are among the leafy vegetables that could be helpful to suggest as a part of daily meal for health benefits and pharmaceutical purposes.
\end{abstract}

\section{Introduction}

Vitamin $\mathrm{E}$ is an important antioxidant nutrient that can delay or inhibit oxidation of the cell membrane. Tocopherols and tocotrienols are generally constituents of vitamin $\mathrm{E}$ compounds which differ in their saturation state of isoprenoid side chain. The main natural sources of vitamin $\mathrm{E}$ are plant oils, whereas vegetables have smaller amounts. Vitamin $\mathrm{E}$ has hypocholesterolemic, anticancer, neuroprotective, and antioxidant properties [1,2]. Green leafy vegetables are recognized for both human and animal feed because of their nutritional value and their health benefits such as biological and antioxidant activities. Among the isomers of tocopherol, the $\alpha$-tocopherol has been considered to be the main contributing isomer form to vitamin $\mathrm{E}$ activity in the human body [3]. However, many recent studies have shown the great importance of the presence of other isomer forms ( $\gamma$ - and $\delta$-tocopherol) in addition to $\alpha$-tocopherol to achieve optimal biological effects [4]. Also, recent studies revealed that $\gamma$-tocopherol has the greatest antioxidant activity and biological potency [5]. Furthermore, the $\gamma$-tocopherol has the highest preventive role against cancer, cardiovascular disease [6], and diabetes but $\gamma$-tocopherol is scarcely found in higher amount in plant foods. Additionally, it was reported that $\delta$-tocopherol prevents hormone-dependent breast cancer progression, colon 
carcinogenesis, lung tumorigenesis, and prostate cancer cell growth [7]. Tocopherol from natural sources has been suggested to be an essential part of a diet preventing Alzheimer's disease [8]. Therefore, tocopherol in green leafy vegetables is very important in dietary food to avoid the highest consumption of oils. Similarly, carotenoids are the bioactive compounds found in most plant organs and tissues. The main health benefits of carotenoids are due to their provitamin A and antioxidant activities. However, tocopherol concentration and carotenoid composition in plant depend on the variety, growth stage and time of harvest, environmental and growing management $[9,10]$, and thus their quantity and nutritional quality.

Cassava (Manihot esculenta Crantz) belongs to the family Euphorbiaceae. Cassava storage roots provide carbohydrates for more than 2 billion people in the tropics [11]. It serves as an industrial raw material in pharmaceutical and chemical industries. It is also a source for biofuel as well as animal feed. In Cameroon, cassava storage roots are among the staple food throughout the country and their leaves are used in the combat of malnutrition [12]. In fact, cassava leaves are considered rich in proteins, phenolics, carotenoids, vitamin B, and vitamin E. Edible cassava leaves are among the best green leafy vegetables consumed in different parts of the world. In terms of the lipophilic bioactive compounds, Ching and Mohamed [13] reported only a result of $\alpha$-tocopherol content in shoots of cassava $(4.93 \mathrm{mg} /$ $100 \mathrm{~g}$ dry weight) and Adewusi and Bradbury [14] investigated carotenoid content in cassava leaves harvested at one growth stage; however, there is no information about the profile of specific tocopherol isomers composition and carotenoids content in cassava leaves harvested at different growth stages. On the other hand, there are no data on the effect of varieties and seasons on the tocopherol isomer composition and carotenoid contents in edible cassava leaves grown under natural conditions. To date, the composition of tocopherols and carotenoids is a parameter of increasing interest in evaluating the quality of plant-based dietary food for humans and animals for healthy benefits.

Therefore, the aim of the present study is to investigate for the first time the tocopherol isomers and carotenoid composition by using a high-performance liquid chromatography (HPLC) analysis in various edible cassava leaves harvested at four different growth stages in order to select variety and age with higher levels of these nutrients.

\section{Materials and Methods}

2.1. Experimental Design. Cassava plants (M. esculenta) grown in an experimental open field under natural conditions were utilized in the present study. Fertilizers or pesticides were not applied during the experiment. The experimental field is conducted in completely randomized blocks with four repetitions of five plots separated by three $2 \mathrm{~m}$ rows. Each plot contained 25 plants of cassava. Edible cassava leaves from the top (from third to fifth young) were sampled at different growing ages at three-month intervals up to 15 months after planting (MAP). During each sampling time, the inner line of plants of different varieties from each plot was considered. In each plot, two inner plants were considered, and a total of 40 cassava plants of each variety were sampled at each harvest date during the experiment; however, it was not only the plants in each plot that were sampled on the four harvest dates; other plants of cassava were considered in order to harvest only the healthy leaves. In addition, the cassava leaves were harvested in both dry and wet seasons.

2.2. Sample Preparation. The 92/0326, 96/1414, 4115, EN, and $\mathrm{AD}$ varieties leaves were washed, cut into pieces, and oven dried at a temperature of $60^{\circ} \mathrm{C}$ for $24 \mathrm{~h}$ (UN75 Memmert Loading-Models 30-750, Federal Republic of Germany). The leaves were then reduced into a powder manually using a mortar and a pestle. The ground material was sieved through a $200 \mu \mathrm{m}$ mesh and stored tightly in an opaque polystyrene bag prior to analysis. The $\alpha-, \gamma$-, and $\delta$-tocopherol contents and $\beta$-carotene or provitamin $\mathrm{A}$ in edible cassava leaves were evaluated at 6MAP, 9MAP, 12MAP, and 15MAP.

2.3. Chemicals and Reagents. All authentic reference standards (purity $>99 \%$ ) of $\alpha$-, $\gamma^{-}$, and $\delta$-tocopherols and $\beta$-carotene HPLC grade were obtained through SigmaAldrich (Mumbai, India). Milli-Q-Water (Millipore, Bedford, MA, USA) was obtained from Engineering Department of the Institute (Central Food Technological Research Institute, CFTRI). Other chemicals and reagents used were of analytical grade purchased from Sisco Research Laboratory (SRL) (Bengaluru, India).

2.4. Saponification and Extraction. Briefly, $100 \mathrm{mg}$ of leaf powder sample was homogenized in $10 \mathrm{ml}$ hexane and $10 \mathrm{ml}$ methanol. After homogenization, the mixture was shaken at $30 \mathrm{rpm}$ in water bath with refluxing tube for $4 \mathrm{~h}$ at $80^{\circ} \mathrm{C}$ and then cooled at room temperature. The solvent was evaporated at $60^{\circ} \mathrm{C}$ and the residue was dried until constant weight. After weighing, the dry residue was mixed with $10 \mathrm{ml}$ of methanol containing $\mathrm{KOH}(5 \mathrm{~N})$ and kept in a water bath as described above, cooled, and filtered. The residues were then washed with hexane and chloroform $(2: 1, \mathrm{v} / \mathrm{v})$. In the last step, $6 \mathrm{ml}$ of hexane (HPLC) was added to the mixture and then $2 \mathrm{ml}$ of $\mathrm{NaCl}$ (5\%) solution was added for the separation phase and allowed to stand for $30 \mathrm{~min}$ after centrifugation $(10 \mathrm{~min})$ at $10000 \mathrm{rpm}$ at $4^{\circ} \mathrm{C}$ before the hexane layer was collected, transferred to a glass tube, and evaporated until dryness in an hot air oven. The residue was dissolved in HPLC solvent, vortexed for $1 \mathrm{~min}$, and filtered with a membrane filter, $0.22 \mu \mathrm{m}$, using syringe filters and kept at $-20^{\circ} \mathrm{C}$ for analysis.

\subsection{Spectrophotometric Determination of Total Vitamin E} Content. The total vitamin $\mathrm{E}$ content of the cassava leaves sample was analysed by the method previously reported [15] with some modifications using a microplate reader (Tecan SPARK 10M, V1.2.20, Austria). We mixed $40 \mu \mathrm{L}$ of extracts of sample, blank, control (chloroform), or standard with 
$80 \mu \mathrm{l}$ of chromogen reagent $(0.6 \mathrm{M}$ sulfuric acid, $28 \mathrm{mM}$ sodium phosphate monobasic, and $4 \mathrm{mM}$ ammonium molybdate) and incubated the mixture for $10 \mathrm{~min}$ at room temperature. Then, the samples were incubated in a shaker water bath at $50 \mathrm{rpm}$ for $90 \mathrm{~min}$ at $37^{\circ} \mathrm{C}$. The absorbance was measured at $695 \mathrm{~nm}$ after cooling at room temperature for $10 \mathrm{~min}$. Values were expressed as mean of four replicates \pm SD in microgram $\alpha$-tocopherol equivalents per gram of sample dry weight ( $\mu \mathrm{g} \alpha-\mathrm{TE} / \mathrm{gdw})$.

2.6. High-Performance Liquid Chromatographic Conditions. A normal-phase HPLC (Waters e2695 Alliance, version 2008, USA) equipped with an autosampler and fluorescence detector (excitation and emission: 296 and 335, respectively) was used to separate and quantify all tocopherols isomers using C18 column. Empower 3 Software (2010) "Solution LC" (USA Corporation, Washington, USA) was used for data acquisition. Isocratic mobile phase contained methanol of HPLC grade and Milli-Q water of HPLC grade $(9: 1)$ at a flow rate of $1 \mathrm{ml} / \mathrm{min}$ and for a total run time $15 \mathrm{~min}$. An aliquot of $20 \mu \mathrm{l}$ was injected automatically in the HPLC column. Each analysis was carried out in triplicate. Peak identification was carried out by comparing the retention times with authentic tocopherol isomers and confirmed with their spectral characteristics obtained from the PDA. Calibration curves for $\alpha$-, $\gamma^{-}$, and $\delta$-tocopherols were plotted using six levels of analytes.

The content of biologically active vitamin $\mathrm{E}(\alpha-\mathrm{TE})$ was calculated using the formula described by Bramley et al. [3]: $\alpha-\mathrm{TE}=\mathrm{C} \alpha+\mathrm{C} \beta \times 0.5+\mathrm{C} \gamma \times 0.1+\mathrm{C} \delta \times 0.03$ and where $\mathrm{C} \alpha=\alpha$-tocopherol content; $\mathrm{C} \beta=\beta$-tocopherol content; $\mathrm{C} \gamma=\gamma$-tocopherol content; and $\mathrm{C} \delta=\delta$-tocopherol content.

$\beta$-Carotene was also identified and quantified by a normal phase HPLC (Waters e2695 Alliance, version 2008, USA) equipped with an autosampler and PDA, UV-visible detector. The C18 column was used for separation and acetonitrile/methanol/dichloromethane (75/25/5) containing $0.05 \%$ triethylamine (in order to improve carotenoids recovery from the chromatographic column) was used as mobile phase to separate carotenoids. Methanol also contains $0.05 \%$ ammonium acetate. An aliquot of $20 \mu \mathrm{L}$ was injected automatically into the HPLC system under isocratic condition with the flow rate of $1 \mathrm{ml} / \mathrm{min}$ and temperature maintained at $25^{\circ} \mathrm{C}$ for a $30 \mathrm{~min}$ total run. The spectra were recorded in the range of $200-700 \mathrm{~nm}$ and chromatograms were obtained at $450 \mathrm{~nm}$.

2.7. Statistical Analysis. Statistical analyses of all data were performed using Statgraphics software (version. 16). XLSTAT software (version.16) was used to perform principal component analysis. Tukey's (HSD) test was used to determine any significant difference between different varieties for each variety and the significance was accepted at level $p<0.05$. All experiments were done in triplicate or quadruplicate and were analysed by one-way and two-way analysis of variance (ANOVA). The results were expressed as means \pm standard deviation.

\section{Results and Discussion}

3.1. Total Vitamin E Content of Five Edible Cassava Leaves Harvested at Different Ages. Vitamin E (tocopherol and tocotrienol) is the most potent lipophilic antioxidant that is synthesized in photosynthetic organisms. As shown in Figure 1, the total vitamin E content varied greatly among the cassava leaves harvested in each date (6MAP, 9MAP, 12MAP, and 15MAP). Cassava leaves of AD variety showed the highest value $(222 \mu \mathrm{g} \alpha$-TE/gdw $)$ among leaves at 6MAP; however, there was no significant $(p>0.05)$ difference in value $(221 \mu \mathrm{g} \alpha$-TE/gdw $)$ with the $\mathrm{EN}$ variety during this harvest date. The leaves of the 96/1414 variety had a low concentration $(156 \mu \mathrm{g} \alpha-\mathrm{TE} / \mathrm{gdw})$ of total vitamin $\mathrm{E}$ compared to the others. Then, total vitamin E decreased significantly $(p<0.05)$ in all cassava leaves at 9MAP except the $96 / 1414$ variety $(167 \mu \mathrm{g} \alpha-\mathrm{TE} / \mathrm{gdw})$. However, the total vitamin $\mathrm{E}$ concentration increased at $12 \mathrm{MAP}$ in cassava leaves of 4115 (203 $\mu \mathrm{g} \alpha$-TE/gdw), 92/0326 (177 $\mu \mathrm{g} \alpha$-TE/gdw), and EN (147 $\mu \mathrm{g} \alpha$-TE/gdw) varieties with the exception of the AD (152 $\mu \mathrm{g} \alpha$-TE/gdw) and 96/1414 (142 $\mu \mathrm{g} \alpha$-TE/gdw) varieties whose total vitamin $\mathrm{E}$ concentrations decreased slightly as seen in Figure 1. These results indicate that genetic variability did not greatly affect vitamin $\mathrm{E}$ active content according to two-way factor analysis. At 15MAP the cassava leaves of 4115 variety showed again the highest concentration $(205.03 \mu \mathrm{g} \alpha$-TE/gdw) of vitamin E, while the leaves of EN variety had significantly the lowest value $(124 \mu \mathrm{g} \alpha$-TE/ $\mathrm{gdw}$ ) (Figure 1). The results suggest that total vitamin $\mathrm{E}$ content varied with varieties at different harvests of cassava leaves; however, the date of harvesting leaves affected significantly $(p$ value $=0.000)$ vitamin $E$ content confirmed by two-way factor analysis. These changes may not affect the nutritional potential of edible leaves.

3.2. Variation of Tocopherol Isomers Composition during Harvesting Ages of Five Edible Cassava Leaves. The isomers $\alpha$-, $\gamma$-, and $\delta$-tocopherol were identified and quantified in all edible cassava leaves. As presented in Table 1, it appears that the amounts of tocopherol isomers composition varied significantly $(p<0.05)$ among the edible cassava leaves. The $\gamma$-tocopherol content was found in much higher levels $(1365 \mu \mathrm{g} / 100 \mathrm{gdw})$ in the leaves of EN variety than in any other samples. Besides, $\alpha$-tocopherol equivalents and the total tocopherol index were found to be higher again in the same leaves. Furthermore, the $\delta$-tocopherol content was the lowest $(12 \mu \mathrm{g} / 100 \mathrm{gdw})$ in the $92 / 0326$ variety, while the $\delta$-tocopherol content was higher in leaves of 96/1414 variety $(319 \mu \mathrm{g} / 100 \mathrm{gdw})$ and $\mathrm{AD}$ variety $(386 \mu \mathrm{g} / 100 \mathrm{gdw})$ as compared to other varieties with respect to $\alpha$-tocopherol contents. In comparison with previous studies on the $\alpha$-tocopherol content (57 mg/100 gdw) of Ficus carica leaves reported [16], the amount of $\alpha$-tocopherol was least in the cassava leaves. The differences in the levels of this amount are probably due to the cultivars, plant ages, and also the temperatures used in drying the leaves. Also, the content of tocopherol isomers in the leaves harvested at 9MAP varied greatly according to the variety (Table 2). The variation 


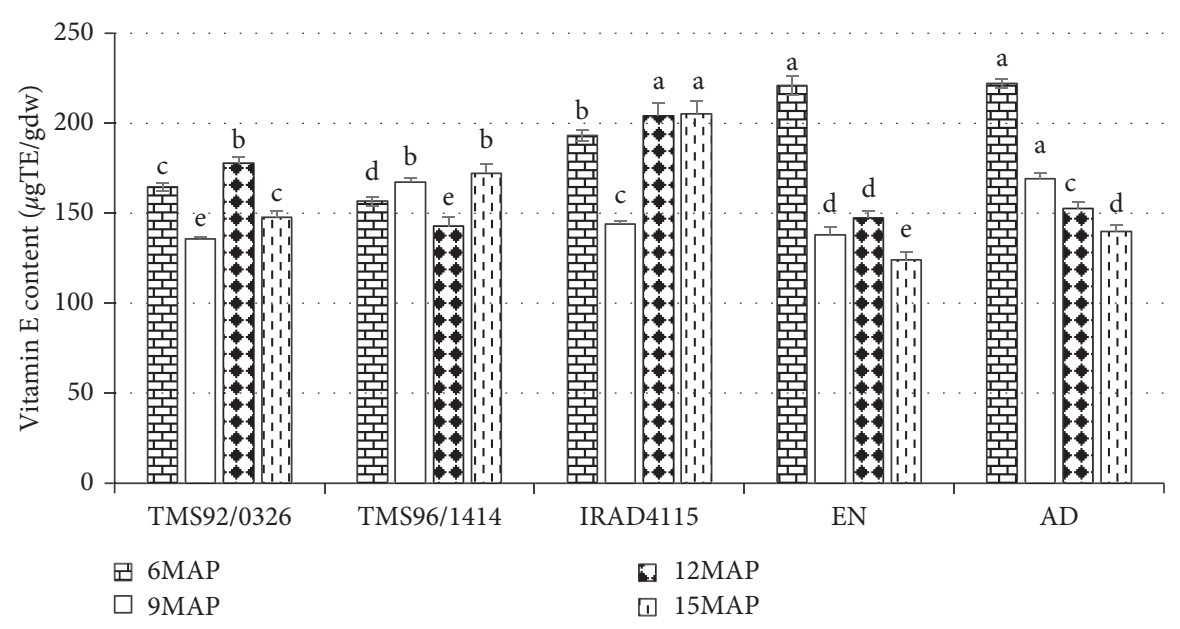

Figure 1: Total vitamin E of edible cassava leaf variety at different harvest ages. Values are given in micrograms per gram of sample dry weight $(\mu \mathrm{g} / \mathrm{gdw})$; MAP: months after planting. Cassava leaves varieties were harvested at $6 \mathrm{MAP}$ (onset of dry season, $15-20^{\circ} \mathrm{C}, 00 \mathrm{~mm}$ ), 9MAP (main dry season, $35-40^{\circ} \mathrm{C}, 00 \mathrm{~mm}$ ), 12MAP (onset of rainy season, $20-30^{\circ} \mathrm{C}, 300-500 \mathrm{~mm}$ ), and $15 \mathrm{MAP}$ (rainy season, $15-25^{\circ} \mathrm{C}$, 9500-1100 mm) months after planting. Values are expressed in microgram tocopherol equivalent per gram dry weight basis ( $\mu \mathrm{g} \alpha-\mathrm{TE} / \mathrm{gdw})$. Values are mean \pm standard deviation; $n=4$; bars followed by different lowercase letters are significantly $(p<0.05)$ different for the same harvest age. Two-way ANOVA: variety $(p$ value $=0.040)$; MAP $(p$ value $=0.000)$; variety $\times$ MAP $(p$ value $=0.731)$.

TABLE 1: Tocopherol isomers content of edible cassava leaf variety harvested in onset of dry season at 6 months after planting (6MAP, $\left.15-20^{\circ} \mathrm{C}, 00 \mathrm{~mm}\right)$.

\begin{tabular}{lccccc}
\hline Varieties & $92 / 0326$ & $96 / 1414$ & 4115 & EN & AD \\
\hline$\alpha$-Toc & $135.66 \pm 6.73^{\mathrm{e}}$ & $305.63 \pm 7.68^{\mathrm{c}}$ & $584.46 \pm 6.31^{\mathrm{b}}$ & $961.30 \pm 6.78^{\mathrm{a}}$ & $193.95 \pm 6.85^{\mathrm{d}}$ \\
$\gamma$-Toc & $186.08 \pm 1.69^{\mathrm{e}}$ & $431.90 \pm 13.69^{\mathrm{d}}$ & $728.85 \pm 23.03^{\mathrm{c}}$ & $2782.55 \pm 6.48^{\mathrm{a}}$ & $790.26 \pm 6.80^{\mathrm{b}}$ \\
$\delta$-Toc & $12.69 \pm 0.09^{\mathrm{e}}$ & $319.90 \pm 0.19^{\mathrm{b}}$ & $302.51 \pm 0.03^{\mathrm{c}}$ & $174.37 \pm 0.28^{\mathrm{d}}$ & $386.82 \pm 0.03^{\mathrm{a}}$ \\
$\alpha$-TE & $154.65 \pm 1.31$ & $358.42 \pm 0.63$ & $666.42 \pm 2.23$ & $1244.79 \pm 0.45$ & $284.58 \pm 1.08$ \\
Toco index & $334.43 \pm 2.84$ & $1057.43 \pm 7.19$ & $1615.82 \pm 9.79$ & $3918.22 \pm 6.77$ & $1370.21 \pm 4.56$ \\
\hline
\end{tabular}

Values are given in micrograms per 100 gram of sample dry weight basis $(\mu \mathrm{g} / 100 \mathrm{gdw})$.Toc: tocopherol; $\alpha$-TE: $\alpha$-tocopherol equivalent or content of biologically active vitamin $\mathrm{E}$; values are mean \pm standard deviation; $n=3$. Values with the different uppercase letter in the same line are significantly $(p \leq 0.05)$ different.

TABle 2: Tocopherol isomers content of edible cassava leaf variety harvested in dry season at 9 months after planting $\left(9 \mathrm{MAP}, 35-40^{\circ} \mathrm{C}\right.$, $00 \mathrm{~mm})$. Values are given in micrograms per 100 gram of sample dry weight basis $(\mu \mathrm{g} / 100 \mathrm{gdw})$.

\begin{tabular}{lccccc}
\hline Varieties & $92 / 0326$ & $96 / 1414$ & 4115 & EN & AD \\
\hline$\alpha$-Toc & $232.02 \pm 6.13^{\mathrm{c}}$ & $262.49 \pm 7.62^{\mathrm{b}}$ & $228.69 \pm 4.91^{\mathrm{c}}$ & $287.99 \pm 5.24^{\mathrm{a}}$ & $128.12 \pm 6.27^{\mathrm{d}}$ \\
$\gamma$-Toc & $456.63 \pm 31.92^{\mathrm{d}}$ & $523.24 \pm 11.00^{\mathrm{bc}}$ & $537.96 \pm 24.26^{\mathrm{b}}$ & $777.44 \pm 12.15^{\mathrm{a}}$ & $325.87 \pm 10.82^{\mathrm{e}}$ \\
$\delta$-Toc & $99.89 \pm 0.97^{\mathrm{c}}$ & $1158.14 \pm 8.19^{\mathrm{a}}$ & $137.31 \pm 0.43^{\mathrm{b}}$ & $137.26 \pm 0.25^{\mathrm{b}}$ & $86.40 \pm 2.68^{\mathrm{d}}$ \\
$\alpha$-TE & $280.68 \pm 7.23$ & $349.55 \pm 2.57$ & $286.61 \pm 8.21$ & $369.85 \pm 3.01$ & $164.16 \pm 4.89$ \\
Toco index & $788.54 \pm 13.01$ & $1943.87 \pm 5.27$ & $903.96 \pm 9.87$ & $1202.69 \pm 5.88$ & $540.39 \pm 6.59$ \\
\hline
\end{tabular}

Toc: tocopherol; $\alpha$-TE: $\alpha$-tocopherol equivalent or content of biologically active vitamin E; values are mean \pm standard deviation; $n=3$. Values with the different letters in the same line are significantly $(p \leq 0.05)$ different.

observed in the study was in agreement with the findings of [17] who reported a wide variation of tocopherol in kale and collard varieties. At this growth stage, the $\delta$-tocopherol content was the highest among all tocopherol isomers with a value of $1158 \mu \mathrm{g} / 100 \mathrm{gdw}$ shown by the $96 / 1414$ variety as well as the total tocopherol index $(1202 \mu \mathrm{g} / 100 \mathrm{gdw})$. However, the highest value of the $\alpha$-tocopherol equivalents or the content of biologically active vitamin E $(369 \mu \mathrm{g} /$ $100 \mathrm{gdw}$ ) was observed in leaves of the EN variety. The lowest content of tocopherol isomers was $\delta$-tocopherol content measured in the leaves of the AD variety $(86 \mu \mathrm{g} /$ $100 \mathrm{gdw})$. The content of $\alpha$-tocopherol decreased significantly $(p<0.05)$ in all leaves combined with an increase in $\gamma$-tocopherol content in 92/0326, 96/1414, and 4115 varieties estimated as 994, 1365, and $811 \mu \mathrm{g} / 100 \mathrm{gdw}$, respectively (Table 3 ). However, the leaves of the EN variety showed again a higher content of biologically active vitamin E $(299 \mu \mathrm{g} / 100 \mathrm{gdw})$. These results suggest that season markedly impacted the tocopherol isomers composition; however, the effects vary with variety as reported by Lampi et al. [18] who found that the $\alpha$-tocopherol contents $(9-19 \mu \mathrm{g} / 100 \mathrm{gdw}$ and $11-16 \mu \mathrm{g} / 100 \mathrm{gdw}$ in winter and spring, respectively) varied significantly among 6 types of wheat. At $15 \mathrm{MAP}$ as shown in Table 4 , there is a greater 
TABLE 3: Tocopherol isomers content of edible cassava leaf variety harvested in onset of rainy season at 12 months after planting (12MAP, $20-30^{\circ} \mathrm{C}$, and $300-500 \mathrm{~mm}$ ).

\begin{tabular}{lccccc}
\hline Varieties & $92 / 0326$ & $96 / 1414$ & 4115 & EN & AD \\
\hline$\alpha$-Toc & $36.89 \pm 0.48^{\mathrm{e}}$ & $159.64 \pm 9.66^{\mathrm{b}}$ & $87.27 \pm 1.15^{\mathrm{c}}$ & $225.88 \pm 5.83^{\mathrm{a}}$ & $73.05 \pm 2.46^{\mathrm{d}}$ \\
$\gamma$-Toc & $994.96 \pm 16.08^{\mathrm{b}}$ & $1365.10 \pm 14.30^{\mathrm{a}}$ & $811.88 \pm 6.35^{\mathrm{c}}$ & $584.97 \pm 5.86^{\mathrm{d}}$ & $75.19 \pm 0.25^{\mathrm{e}}$ \\
$\delta$-Toc & $37.28 \pm 0.92^{\mathrm{e}}$ & $294.60 \pm 0.02^{\mathrm{c}}$ & $1161.69 \pm 2.85^{\mathrm{a}}$ & $518.36 \pm 0.24^{\mathrm{b}}$ & $110.28 \pm 2.45^{\mathrm{d}}$ \\
$\alpha$-TE & $166.73 \pm 1.04$ & $230.05 \pm 2.89$ & $203.31 \pm 3.95$ & $299.93 \pm 1.04$ & $83.88 \pm 0.97$ \\
Toco index & $1069.13 \pm 5.82$ & $1819.34 \pm 7.99$ & $2060.84 \pm 3.57$ & $1329.21 \pm 3.98$ & $258.52 \pm 1.74$ \\
\hline
\end{tabular}

Values are expressed in micrograms per 100 grams of sample dry weight basis $(\mu \mathrm{g} / 100 \mathrm{gdw})$. Toc: tocopherol; $\alpha$-TE: $\alpha$-tocopherol equivalent or content of biologically active vitamin $\mathrm{E}$; values are mean \pm standard deviation; $n=3$. Values with the different letters in the same line are significantly $(p \leq 0.05)$ different.

TABLE 4: Tocopherol isomers content of edible cassava leaf variety harvested in rainy season at 15 months after planting $\left(15 \mathrm{MAP}, 15-25^{\circ} \mathrm{C}\right.$, and $950-1100 \mathrm{~mm}$ ).

\begin{tabular}{lcccrr}
\hline Varieties & $92 / 0326$ & $96 / 1414$ & 4115 & EN & AD \\
\hline$\alpha$-Toc & $132.94 \pm 11.26^{\mathrm{c}}$ & $42.37 \pm 4.49^{\mathrm{d}}$ & $11.34 \pm 0.16^{\mathrm{e}}$ & $280.92 \pm 6.61^{\mathrm{a}}$ & $105.09 \pm 4.81^{\mathrm{c}}$ \\
$\gamma$-Toc & $1684.82 \pm 16.57^{\mathrm{b}}$ & $380.01 \pm 8.95 c^{\mathrm{d}}$ & $2609.70 \pm 23.06^{\mathrm{a}}$ & $386.03 \pm 6.29^{\mathrm{c}}$ & $192.45 \pm 5.05^{\mathrm{e}}$ \\
$\delta$-Toc & $22.29 \pm 1.97^{\mathrm{e}}$ & $190.60 \pm 3.22^{\mathrm{c}}$ & $582.30 \pm 1.46^{\mathrm{a}}$ & $110.57 \pm 1.56^{\mathrm{d}}$ & $481.11 \pm 2.16^{\mathrm{b}}$ \\
$\alpha$-TE & $302.09 \pm 3.76$ & $86.09 \pm 2.78$ & $289.78 \pm 5.01$ & $322.84 \pm 5.68$ & $138.77 \pm 3.83$ \\
Toco index & $1840.05 \pm 9.93$ & $612.95 \pm 5.55$ & $3203.34 \pm 8.23$ & $777.52 \pm 4.82$ & $778.56 \pm 4.01$ \\
\hline
\end{tabular}

Values are given in micrograms per 100 grams of sample dry weight basis $(\mu \mathrm{g} / 100 \mathrm{gdw})$. Toc: tocopherol; $\alpha$-TE: $\alpha$-tocopherol equivalent or content of biologically active vitamin E; values are mean \pm standard deviation; $n=3$. Values with the different letters in the same line are significantly $(p \leq 0.05)$ different.

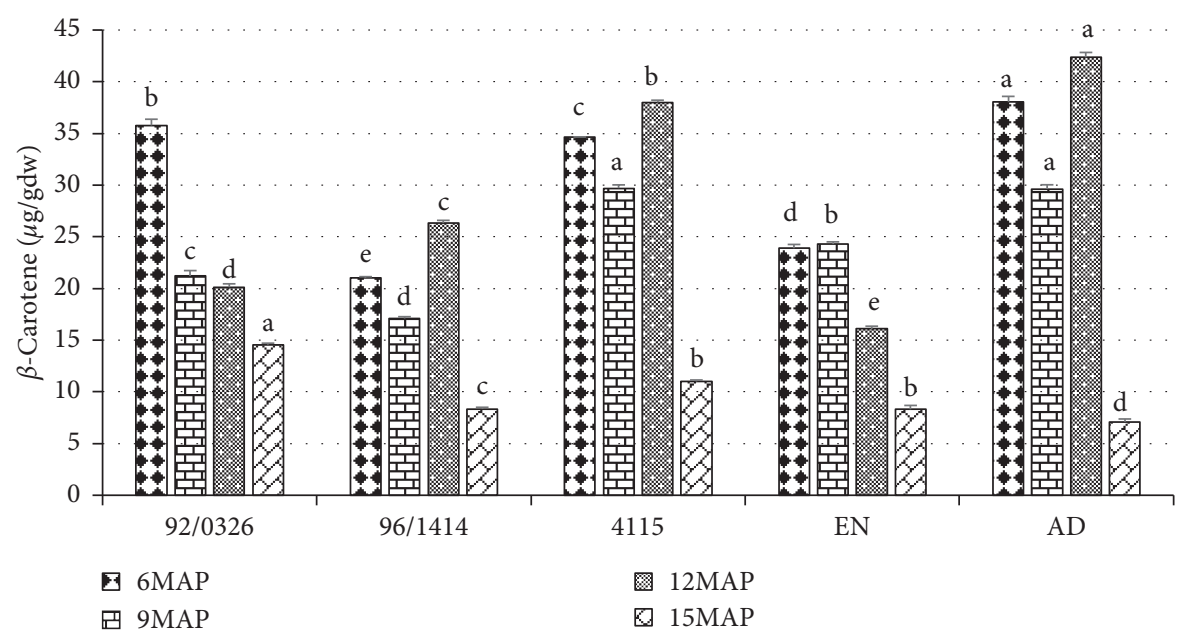

Figure 2: $\beta$-Carotene content of edible cassava leaf variety at different harvest ages. Values are given in micrograms per gram of sample dry weight $(\mu \mathrm{g} / \mathrm{gdw})$; MAP: months after planting. Cassava leaves varieties were harvested at $6 \mathrm{MAP}$ (onset of dry season, $15-20^{\circ} \mathrm{C}, 00 \mathrm{~mm}$ ), 9MAP (main dry season, $35-40^{\circ} \mathrm{C}, 00 \mathrm{~mm}$ ), $12 \mathrm{MAP}$ (onset of rainy season, $20-30^{\circ} \mathrm{C}, 300-500 \mathrm{~mm}$ ), and $15 \mathrm{MAP}$ (rainy season, $15-25^{\circ} \mathrm{C}$, 9500-1100 mm) months after plantation. Values are expressed in microgram per gram dry weight basis $(\mu \mathrm{g} / \mathrm{gdw})$. Values are mean\pm standard deviation; $n=3$; bars followed by different lowercase letters are significantly $(p<0.05)$ different for the same harvest age. Twoway ANOVA: variety $(p$ value $=0.050)$; MAP $(p$ value $=0.000)$; variety $\times$ MAP $(p$ value $=0.105)$.

variation of tocopherol isomers content with the decrease of $\alpha$-tocopherol content in $96 / 1414$ and 4115 varieties. A similar decrease in $\gamma$-tocopherol content was noted in 96/ 1414 and EN varieties. However, the content of biologically active vitamin $\mathrm{E}$ was found in leaves of the $\mathrm{EN}$ variety $(322 \mu \mathrm{g} / 100 \mathrm{gdw})$ and the total tocopherol index as well as the highest concentration $(2609 \mu \mathrm{g} / 100 \mathrm{gdw})$ of $\gamma$-tocopherol was obtained in the 4115 variety. These strong variations in tocopherol isomers contents during different growth stages and seasons agree with statements of many researchers $[13,18-20]$ that the concentration of tocopherol isomers may differ significantly based on development stage of plants and environmental conditions such as light intensity, season, and water stress. Results obtained demonstrate that cassava leaves of the EN variety harvested at $6 \mathrm{MAP}$ have the highest content of biologically active vitamin E.

3.3. Effect of Harvesting Ages of Five Edible Cassava Leaves on $\beta$-Carotene Content (Provitamin A). The green leafy vegetables are considered as a natural source of carotenoids 


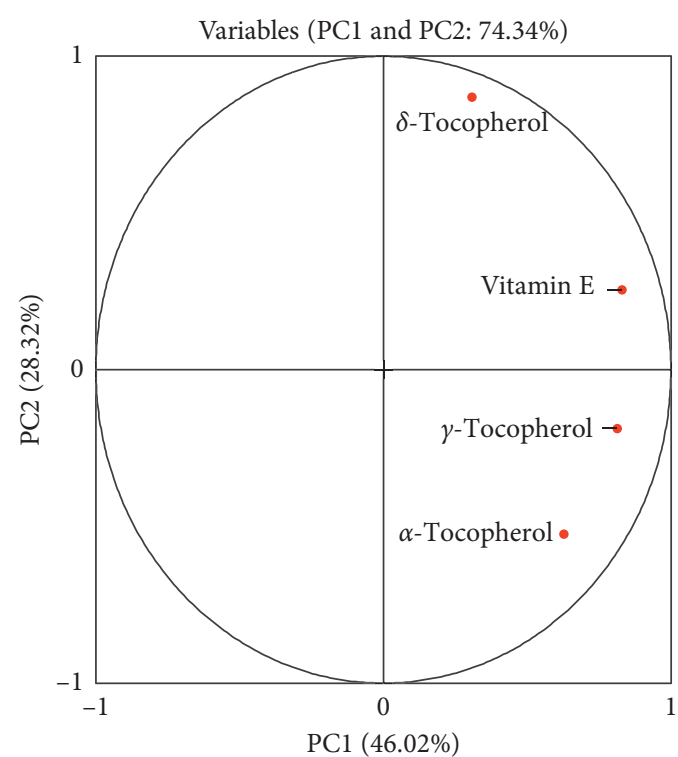

(a)

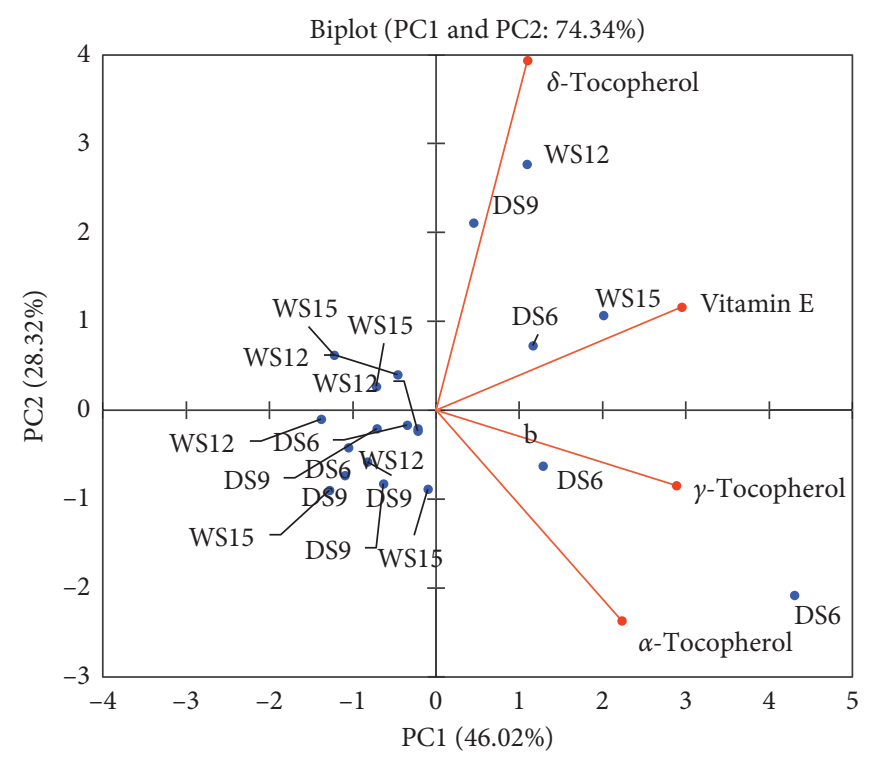

(b)

Figure 3: Principal component analysis (PCA) mean showing the relationship among total vitamin E tocopherol isomers and effects of growth stages and seasons on their contents. (a) Correlation between variables and factors and (b) biplot. DS6: dry season at 6MAP; DS9: adry season at 9MAP; DS12: dry season at 12MAP; DS15: dry season at 15MAP; WS6: 'bet season at 6MAP; WS9: wet season at 9MAP; WS12: wet season at 12MAP; WS15: wet season at 15MAP.

which exert biological activity on human health; however, their concentration differed within the varieties according to the growth stages as well as climatic conditions. Figure 2 presents the $\beta$-carotene content in the edible leaves harvested during four different growth ages and seasons. The content of $\beta$-carotene in edible cassava leaves of $\mathrm{AD}$ variety was the highest ( $38 \mu \mathrm{g} / \mathrm{gdw})$ at $6 \mathrm{MAP}$ as compared to other samples; however, the lowest value $(21 \mu \mathrm{g} / \mathrm{gdw})$ of $\beta$-carotene content was obtained in the 96/1414 variety (Figure 2 ). Furthermore, Figure 2 shows that the content of $\beta$-carotene decreased in all samples at 9MAP except in the leaves of the EN variety whose value was not changed significantly $(p<0.05)$. These results are similar to those obtained [21] during their study on nutrients of cassava meal of threes age plant of five cassava varieties in Brazil, while the 4115 variety showed the highest value $(29 \mu \mathrm{g} / \mathrm{gdw})$ at 9 MAP followed by the $\mathrm{AD}$ variety. The decrease of content of $\beta$-carotene (provitamin A) coincides with the main dry season $\left(35^{\circ} \mathrm{C}-40^{\circ} \mathrm{C}\right.$ and $00 \mathrm{~mm}$ for temperature and rainfall, respectively). This result is in agreement with Mibei et al. [22] who reported a significant decrease in carotenoids with drought stress on African eggplant accessions. However, $\beta$-carotene content increased significantly $(p<0.05)$ in all samples at 12MAP with the highest value $(42 \mu \mathrm{g} / \mathrm{gdw})$ observed in leaves of the $\mathrm{AD}$ variety followed by the 4115 variety (Figure 2 ). These variations in $\beta$-carotene content in cassava leaves were reported [21] on five cassava varieties harvested at 12MAP, 15MAP, and 17MAP with the level values of 11 to $137 \mathrm{mg} / 100 \mathrm{gdw}, 50$ to $70 \mathrm{mg} / 100 \mathrm{gdw}$, and 58 to $92 \mathrm{mg} / 100 \mathrm{gdw}$, respectively. The $\beta$-carotene content variation may be due to the onset of the rainy season $\left(20-30^{\circ} \mathrm{C}\right.$ and $300-500 \mathrm{~mm}$ for temperature and rainfall, respectively) which favors the synthesis of $\beta$-carotene in cassava leaves. In contrast, $\beta$-carotene content decreased significantly $(p<0.05)$ again in all samples at 15MAP that coincide with the main rainy season $\left(15-25^{\circ} \mathrm{C}\right.$ and 9500-1100 $\mathrm{mm}$ for temperature and rainfall, respectively). However, the lowest value $(14 \mu \mathrm{g} / \mathrm{gdw})$ was found in leaves of the $92 / 0326$ variety (Figure 2 ). These results suggest that the main rainy season negatively affected $\beta$-carotene content in cassava leaves as observed in [21]. These findings were also similar to that previously reported by Lakshminarayana et al. [23], who found that carotenoids in leafy vegetables markedly vary with variety, degree maturity, and season.

3.4. Principal Component Analysis (PCA). PCA is one useful statistical accurate tool for the analysis of several samples and variables in order to establish their differences and similarities. In this study, PC1 and PC2 explained a variation of $74 \%$ of the total variance in the data (Figure 3). PC1 described $46 \%$ of the total information and PC2 explained $28 \%$ of the variability of factors. The $\gamma$-tocopherol and vitamin E contents showed a positive strong correlation followed by $\alpha$-tocopherol and $\gamma$-tocopherol while $\alpha$-tocopherol and $\delta$-tocopherol correlated negatively (Figure 3(a)). The variable most positively correlating to PC2 was $\gamma$-tocopherol placed alone and also WS12 followed by DS9 contributed more to the content variation, while other tocopherol isomers and vitamin E mostly correlated with PC1 (Figure 3(b)), thereby causing greater variability among the samples. The $\delta$-tocopherol and $\gamma$-tocopherol contents were positively affected by DS6. However, vitamin E was impacted positively by WS15 and DS6 and correlated positively with PC1 (Figure 3(b)). The results indicated that the growth stages and seasons had a crucial effect on the total vitamin $\mathrm{E}$ 
and tocopherol isomers content variation of edible cassava leaves. Therefore, the study of the harvest growth stage and season is very important to gain the best yield of this functional food ingredient. Also, the selection of cassava variety for growing by breeders may have a significant impact on vitamin E content bioactive compounds.

\section{Conclusions}

The present study investigated the lipophilic bioactive in various leaves of cassava plants harvested at four different harvest ages. Two major lipophilic nutrients were analysed, vitamin $\mathrm{E}$ and $\beta$-carotene, and the tocopherol isomers were identified and quantified for the first time in the edible cassava leaves. Genetic differences among varieties produced great variation and unexpected tocopherol profile and $\beta$-carotene content as well as seasons. Among the edible leaves, the varieties were not different in total vitamin $\mathrm{E}$ but did vary in $\beta$-carotene content. However, the $\gamma$ - and $\alpha$-tocopherol isomers content were predominant in levels. The highest $\gamma$-tocopherol content $(2782 \mu \mathrm{g} / 100 \mathrm{gdw})$ and $\alpha$-tocopherol equivalents or the content of biologically active vitamin E $(1244 \mu \mathrm{g} / 100 \mathrm{gdw})$ were found in the leaves of EN variety at 6MAP. However, the highest value $(42 \mu \mathrm{g} /$ $100 \mathrm{gdw}$ ) of provitamin A was found in leaves of AD variety harvested at 12MAP. Due to the nutritional and functional compounds they contain, edible cassava leaves are among the leafy vegetables that could be helpful to suggest as a part of daily meal for health benefits and pharmaceutical purposes. Furthermore, the study indicated that the content of carotenoids is affected significantly by different ages of harvest; hence, appropriate harvest time and season may help the consumers to gain the best yield of these nutritional bioactive compounds. Hence, 6MAP is the appropriate harvest time for vitamin $\mathrm{E}$ on basis of $\alpha$-tocopherol equivalent or content of biologically active vitamin $\mathrm{E}$ and provitamin A.

\section{Data Availability}

The data used to support the findings of this study are available from the corresponding author upon reasonable request.

\section{Conflicts of Interest}

The authors declare that there are no conflicts of interest regarding this paper.

\section{Acknowledgments}

Laya Alphonse acknowledges the CSIR-TWAS for supporting the study in the form of fellowship no. 3240293590. The authors also thank CSIR-Central Food Technological Research Institute (CFTRI).

\section{References}

[1] C. K. Sen, S. Khanna, and S. Roy, "Tocotrienols in health and disease: the other half of the natural vitamin E family,"
Molecular Aspects of Medicine, vol. 28, no. 5-6, pp. 692-728, 2007.

[2] M. Schubert, S. Kluge, L. Schmölz et al., "Review. Long-chain metabolites of vitamin E: metabolic activation as a general concept for lipid-soluble vitamins?" Antioxidants, vol. 7, pp. 1-20, 2018.

[3] P. M. Bramley, I. Elmadfa, A. Kafatos et al., "Vitamin E," Journal of the Science of Food and Agriculture, vol. 80, no. 7, pp. 913-938, 2000.

[4] K. Saldeen and T. Saldeen, "Importance of tocopherols beyond $\alpha$-tocopherol: evidence from animal and human studies," Nutrition Research, vol. 25, no. 10, pp. 877-889, 2005.

[5] I. Guzman, G. G. Yousef, and A. F. Brown, "Simultaneous extraction and quantitation of carotenoids, chlorophylls, and tocopherols in brassica vegetables," Journal of Agricultural and Food Chemistry, vol. 60, no. 29, pp. 7238-7244, 2012.

[6] K. Hensley, E. J. Benaksas, R. Bolli et al., "New perspectives on vitamin E: $\gamma$-tocopherol and carboxyethylhydroxychroman metabolites in biology and medicine," Free Radical Biology and Medicine, vol. 36, no. 1, pp. 1-15, 2004.

[7] A. Azzi, "Tocopherols, tocotrienols and tocomonoenols: many similar molecules but only one vitamin E," Redox Biology, vol. 26, Article ID 101259, 2019.

[8] M. C. Morris, D. A. Evans, C. C. Tangney et al., "Relation of the tocopherol forms to incident Alzheimer disease and to cognitive change," The American Journal of Clinical Nutrition, vol. 81, no. 2, pp. 508-514, 2005.

[9] A. Mozafar, Climate and Plant Vitamins. Plant Vitamins: Agronomic, Physiological, and Nutritional Aspects, pp. 89-126, CRC Press, Boca Raton, FL, USA, 1994.

[10] O. Kodad, R. S. I Company, and J. M. Alonso, "Genotypic and environmental effects on tocopherol content in almond," Antioxidants, vol. 7, no. 1, p. 6, 2018.

[11] A. Laya, B. B. Koubala, H. Kouninki, and E. N. Nukenine, "Effect of harvest period on the proximate composition and functional and sensory properties of gari produced from local and improved cassava (Manihot esculenta) varieties," International Journal of Food Science, vol. 2018, Article ID 6241035, 15 pages, 2018.

[12] B. B. Koubala, A. Laya, H. Massaï, H. KouninkI, and E. N. Nukenine, "Physico-chemical characterization leaves from five genotypes of cassava (Manihot esculenta Crantz) consumed in the far north region (Cameroon)," American Journal of Food Science and Technology, vol. 3, no. 2, pp. 40-47, 2015.

[13] L. S. Ching and S. Mohamed, "Alpha-tocopherol content in 62 edible tropical plants," Journal of Agricultural and Food Chemistry, vol. 49, no. 6, pp. 3101-3105, 2001.

[14] S. R. A. Adewusi and J. H. Bradbury, "Carotenoids in cassava: comparison of open-column and hplc methods of analysis," Journal of the Science of Food and Agriculture, vol. 62, no. 4, pp. 375-383, 1993.

[15] P. Prieto, M. Pineda, and M. Aguilar, "Spectrophotometric quantitation of antioxidant capacity through the formation of a phosphomolybdenum complex: specific application to the determination of vitamin E," Analytical Biochemistry, vol. 269, no. 2, pp. 337-341, 1999.

[16] S. Konyahoglu, H. Saglam, and B. Kivcak, " $\alpha$-tocopherol, flavonoid, and phenol contents and antioxidant activity of Ficus carica leaves," Pharmaceutical Biology, vol. 43, no. 8, pp. 683-686, 2005.

[17] M. J. Kim, Y.-C. Chiu, and K.-M. Ku, "Glucosinolates, carotenoids, and vitamins $\mathrm{E}$ and $\mathrm{K}$ variation from selected kale 
and collard cultivars," Journal of Food Quality, vol. 2017, Article ID 5123572, 8 pages, 2017.

[18] A.-M. Lampi, T. Nurmi, V. Ollilainen, and V. Piironen, "Tocopherols and tocotrienols in wheat genotypes in the healthgrain diversity screen," Journal of Agricultural and Food Chemistry, vol. 56, no. 21, pp. 9716-9721, 2008.

[19] D. J. M. Goämez-Coronado and C. Barbas, "Optimized and validated HPLC method for $\alpha$-and $\gamma$-tocopherol measurement in Laurus nobilis leaves. New data on tocopherol content," Journal of Agricultural and Food Chemistry, vol. 51, pp. 5196-5201, 2003.

[20] K. Hormaetxe, R. Esteban, J. M. Becerril, and J. I. GarciaPlazaola, "Dynamics of the alpha-tocopherol pool as affected by external (environmental) and internal (leaf age) factors in Buxus sempervirens leaves," Physiologia Plantarum, vol. 125, no. 3, pp. 333-344, 2005.

[21] C. Wobeto, A. D. Corrêa, C. M. P. D. Abreu, C. D. D. Santos, and J. R. D. Abreu, "Nutrients in the cassava (Manihot esculenta Crantz) leaf meal at three ages of the plant," Ciência e Tecnologia de Alimentos, vol. 26, no. 4, pp. 865-869, 2006.

[22] E. K. Mibei, J. Ambuko, J. J. Giovannoni, A. N. Onyango, and W. O. Owino, "Carotenoid profiling of the leaves of selected African eggplant accessions subjected to drought stress," Food Science \& Nutrition, vol. 5, no. 1, pp. 113-122, 2017.

[23] R. Lakshminarayana, M. Raju, T. T. Thykrishnakantha, and V. Baskaran, "Determination of major carotenoids in a few indian leafy vegetables by high-performance liquid chromatography," Journal of Agricultural and Food Chemistry, vol. 53, no. 8, 2005. 